\title{
A saúde entre a lei e o costume na escola primária paranaense, final dos anos 1910
}

\section{Health between the law and customs in a primary school in Paraná State in the late 1910s}

\author{
Liane Maria Bertucci ${ }^{1}$
}

\begin{abstract}
RESUMO
A partir de determinações do Código do Ensino do Estado do Paraná e do Programa do Grupo Escolar Modelo e Similares, ambos de 1917, o artigo analisa propostas para a escola primária paranaense que se relacionavam com a saúde em um período de divulgação de ideais sanitaristas e teses eugênicas no Brasil. Considerando, como escreveu Edward P. Thompson, que a legislação é resultado de embates, negociações e acordos sociais, o texto destaca o caso da transferência da escola isolada da Graciosa de Baixo para a cidade de Antonina; transferência que teve como argumento central a questão da saúde e motivou diferentes ações de pais de alunos, professora e autoridades governamentais do Paraná durante a segunda quinzena de janeiro de 1917 . O caso da transferência da escola da Graciosa de Baixo possibilitou que fosse vislumbrado como proposta para a saúde, presente no Código do Ensino do Estado do Paraná, no Programa do Grupo Escolar Modelo e Similares e também em relatórios estatuais sobre educação, balizados por costumes de pais de alunos (e de seus filhos) e da professora do estabelecimento escolar, todos imbuídos da importância da educação primária.

Palavras-chave: educação e saúde; legislação; sanitarismo; costume; Paraná.
\end{abstract}

\section{ABSTRACT}

Based on the regulations of the Teaching Code of Paraná State and on the Program for Primary School Teaching and Similar Models, both from 1917,

DOI: $10.1590 / 0104-4060.38205$

1 Universidade Federal do Paraná. Departamento de Teoria e Fundamentos da Educação. Curitiba, Paraná, Brasil. Rua General Carneiro, nº 460, $5^{\circ}$ andar. CEP: 80060-150. 
this article analyzes health-related proposals for primary school teaching in Paraná at a time when public health and themes related to eugenics were becoming widespread in Brazil. Considering, as Edward P. Thompson once wrote, that legislation is the result of conflict, negotiations and social deals, the text highlights the case of the transfer of the isolated Graciosa de Baixo School to the town of Antonina. The central argument for this transfer was health, and this resulted in different reactions from parents of students, the teacher and the state authorities in late January 1917. The transfer of the Graciosa de Baixo School affords a glimpse of proposals for health that could be detected in the Teaching Code of Paraná, in the Program for Primary School Teaching and Similar Models and also in state reports on education that were effectively guided by the customs of parents (and their children) and the teacher at the school. All of these people were concerned with the importance of primary school education.

Keywords: education and health; legislation; public health; customs; Paraná.

\section{Introdução}

No Brasil, muitos dos debates que aconteceram no século XIX, sobre o fim do trabalho escravo e a questão da imigração, atrelaram a ideia de civilidade e progresso do país com a necessidade de formação do homem brasileiro. Museus Etnográficos, Institutos Históricos e Geográficos, além de Faculdades de Medicina e de Direito foram locais privilegiados de reuniões e discussões de indivíduos que pretendiam "refazer" o país e seus habitantes. Teses evolucionistas e o darwinismo social ganharam adeptos e o pessimismo sobre o futuro de uma nação mestiça cresceu. Entretanto, a partir do final dos Oitocentos, paralelamente à vinda de imigrantes europeus, novas formas de interpretar o Brasil e seus moradores (que poderiam ser, pouco a pouco, "branqueados") foram elaboradas e ganharam adeptos (DOMINGUES; SÁ; GLICK, 2003; MAIO; SANTOS, 1996, p. 15-82; NAXARA, 1998; SCHWARCZ, 1993).

Nos primeiros anos do século XX a repercussão do livro Os Sertões de Euclides da Cunha, que denunciava a situação miserável dos mestiços de Canudos (Bahia) como resultado do abandono pelos governantes nacionais (NAXARA, 1998, p. 78-89), e, em 1916, o alerta de Arthur Neiva e Belisário Penna sobre as doenças do sertanejo do Brasil Central (BERTUCCI, 2007, p. 148-158) foram combinados com a difusão dos feitos da medicina experimental e, a partir de meados dos anos 1910, também com a tese eugênica que práticas 
de melhoramento (eugenia "positiva" e "preventiva") ${ }^{2}$ concorreriam para a boa constituição do homem nacional (LIMA; HOCHMAN, 1996; MARQUES, 1994; MOTA, 2003; STEPAN, 2004). O resultado foi a crescente mobilização daqueles que vislumbravam a possibilidade de ações que resgatassem pessoas antes consideradas perdidas para a nação, porque estavam enfermas e, nas palavras de Neiva e Penna, vegetavam "[...] no obscurantismo, entregues a si mesmas" (NEIVA; PENNA [1916], 1999, apud BERTUCCI, 2007, p. 154). Tratar os doentes, erradicar moléstias e educar para a manutenção da saúde; essas metas ganharam as páginas dos jornais e repercussão em todo o país com o movimento sanitarista (HOCHMAN, 1998; SÁ, 2009). Nesse contexto a escola primária, que existia em diferentes partes do território nacional, foi um meio privilegiado para a realização da empreitada de regeneração do brasileiro (BERTUCCI, 2013; MARQUES, 2007; ROCHA, 2003, PYKOSZ; OLIVEIRA, 2009).

Criticada nos últimos tempos do império pelos que pleiteavam uma educação chancelada como moderna, a escola primária foi reorganizada a partir da criação legal do grupo escolar em 1893 (inspirada nas experiências europeia e norte-americana). O primeiro desses estabelecimentos de ensino foi inaugurado na cidade de São Paulo no ano seguinte. Projetada para racionalizar e dar um caráter homogêneo e orgânico ao ensino, essa nova escola tornou-se o modelo republicano de ensino primário (MONARCHA, 1999, p. 165-288; SOUZA, 1998). Da capacitação dos professores ao currículo, do prédio ao mobiliário, tudo no grupo escolar ou escola graduada deveria concorrer para a formação, inclusive saudável, do futuro cidadão.

Nas primeiras décadas do século XX a proposta educacional traduzida pelo grupo escolar espraiou-se pelo Brasil e mesmo para estabelecimentos de ensino primário organizados em outros moldes, como as escolas isoladas ou simples (salas-classes multisseriadas), ${ }^{3}$ e a escola graduada foi balizadora de atividades educacionais (SOUZA, 2008, p. 19-86; VIDAL, 2006).

2 Eugenia "positiva", atenção com a procriação sadia; eugenia "preventiva", combater fatores ambientais (disgênicos) que comprometem o desenvolvimento saudável do ser humano, e "eugenia negativa", impedir a procriação de doentes (cf. MARQUES, 1994; STEPAN, 2004). No Brasil, a eugenia "positiva" e a eugenia "preventiva" ganharam ênfase, entretanto a "eugenia negativa" teve vários adeptos e não foram poucos os debates sobre o tema, inclusive no Paraná (JANZ JUNIOR, 2013; WEGNER; SOUZA, 2013).

3 No Paraná, entre o final do século XIX e primeiras décadas do século XX, além de grupos escolares e escolas isoladas (também particulares, supervisionadas pelo Estado), existia a escola ambulante, que percorria por ano 3 localidades que não tivessem uma escola primária fixa, ficando em cada lugar três meses e meio. A denominação "grupo escolar" por vezes designou a escola reunida ou combinada, que agregava no mesmo local, mas em salas diferentes, duas ou mais classes ou escolas, mas sem a efetiva estrutura de um grupo escolar. Neste texto, a denominação 
No Paraná, o primeiro grupo escolar foi inaugurado em Curitiba, capital do Estado, dia 19 de dezembro de 1903: o Grupo Escolar Xavier da Silva. Apesar da necessidade de outras empreitadas para "modificar a realidade escolar, a fim de aproximá-la do discurso dos poderes públicos", como escreveu Bencostta (2005, p. 101), a inauguração evidenciou o tipo de escola que se pretendia multiplicar no Estado. Nesse período, que coincidiu com significativo aumento populacional do Paraná com grande fluxo imigratório, a instalação de grupos escolares foi mediada por transformações e demandas de uma sociedade cujo número de pessoas saltou de 327.136 moradores em 1900 (aproximadamente 13\% imigrantes) para 685.711 habitantes em 1920 (pouco mais de 9\% estrangeiros)(MARTINS, 1941, p. 55, 96-101. Cf. BUENO, 2004; LAMB, 1999).

Inaugurado em dezembro de 1903, o pioneiro Xavier da Silva estava inconcluso, pois sua edificação e sua inauguração antes do término das obras estavam atreladas aos festejos do cinquentenário da emancipação política do Paraná, que foi comarca de São Paulo até 1853. O prédio do Grupo Escolar, formado por um vestíbulo, seis salas de aula (perpendiculares entre si, três salas na seção feminina e três salas na seção masculina) e dois pátios cobertos para recreios, era uma versão simplificada do modelo paulista e receberia acréscimos em pouco tempo; em suas salas começaram a funcionar seis séries escolares (três em cada seção) (BENCOSTTA, 2005, p. 110-112; CASTRO, 2008, p. 33-34, 46-49). Desde os primeiros dias após sua inauguração relatórios de professores e de autoridades estaduais de ensino denunciavam problemas estruturais do prédio e as condições desfavoráveis de higiene das salas de aula (BENCOSTTA, 2005, p. 113; OLIVEIRA; MEURER, 2007). Consideradas por Oliveira e Meurer indícios de "tensões entre o prescrito e o realizado" (2007, p. 80), algumas dessas denúncias também podem sinalizar estratégias ${ }^{4}$ para que fossem implantadas propostas debatidas na própria esfera governamental, como sugerem as palavras da professora Carolina Pinto Moreira, que em 1908 denunciou o mau estado de conservação e de limpeza do Grupo Escolar Xavier da Silva depois de ter realizado, no ano anterior, visita técnica (comissionada pelo governo paranaense) aos grupos escolares de São Paulo e retornado com sugestões relacionadas à higiene escolar (MOREIRA apud OLIVEIRA; MEURER, 2007, p. 82; MOREIRA, 1907).

"grupo escolar" significa o modelo paulista de "escola primária graduada". Sobre escola reunida, veja as considerações de Lopes (2006, p. 81-107).

4 "Chamo de estratégia o cálculo (ou a manipulação) das relações de forças que se torna possível a partir do momento em que o sujeito de querer e poder (uma empresa, um exército, uma cidade, uma instituição científica) pode ser isolado. A estratégia postula um lugar suscetível de ser circunscrito como algo próprio e ser a base de onde se podem gerir as relações com uma exterioridade de alvos ou ameaças (os clientes ou os concorrentes [...])" (CERTEAU, 2011, p. 93. Grifos do autor). 
Edificado em uma cidade que crescia impulsionada pela riqueza gerada pela exploração da erva-mate, que multiplicou atividades comerciais e industriais na região de Curitiba (BONI, 1998; LAVALLE, 1981; LUZ, 1992; PEREIRA, 1996) $)^{5}$, o Grupo Escolar Xavier da Silva, inclusive com as críticas que recebeu, é um exemplo do multifacetado processo de implantação do modelo da escola graduada no Estado, processo que teve na questão da higiene das pessoas, dos prédios e dos lugares, itens primordiais de discussões, reivindicações e determinações legais, em um período que educação e saúde estavam imbricadas de maneira ímpar.

\section{A lei}

Desde os tempos da Academia Imperial de Medicina, que pautava debates sobre a possibilidade "da educação e instrução da mocidade" concorrer para o desenvolvimento físico e moral do brasileiro, que o tema higiene na escola foi abordado de diferentes perspectivas pelos doutores (GONDRA, 2000, p. 529, 531). "Paradigma dominante" entre o final do século XVIII e início do XIX quando o assunto era civilização (FERREIRA, 2001, p. 208), a higiene manteve relevância com a progressiva difusão da microbiologia, que colocou em xeque a teoria miasmática (CZERESNIA, 1997, p. 41-57; CORBIN, 1987; LATOUR, 1994; SOLOMON-BAYET, 1986; ROSEN, 1994, p. 231-375). Higienizar lugares e coisas e estimular a higiene pessoal tornaram-se então fundamentais para evitar a multiplicação de micróbios deletérios e para manter ou restaurar a saúde das pessoas.

Nos anos 1910, quando as ideias do movimento sanitarista eram discutidas pelos médicos reunidos na Sociedade de Medicina do Paraná (ROSS, 2012) e resultavam em ações governamentais no Estado (KUMMER, 2007; STERN, 2003), o ensino de higiene nas escolas primárias paranaenses ganhou destaque com o Programa do Grupo Escolar Modelo e Similares decretado em junho de 1917, poucos meses após a promulgação, dia 9 de janeiro, de um novo Código do Ensino (PARANÁ, 1917a, 1917b). As mudanças introduzidas por este Código foram elaboradas a partir das considerações emitidas por uma comissão de professores que havia estudado in loco os métodos e a organização dos grupos

5 Segundo os primeiros censos do período republicano, o município de Curitiba contava com 24.553 habitantes em 1890, em 1900 tinha 50.124 moradores e em 1920 somava 78.986 habitantes (Cf.: MARTINS, 1941, p. 94-101). 
escolares em São Paulo, pois apesar de significativas mudanças introduzidas pelo Código do Ensino anterior, decretado em 1915, a escola primária paranaense, segundo autoridades educacionais, ainda carecia de padronização (PARANÁ, 1915; ALBUQUERQUE, 1916, p. 32-34; SANTOS, 1917, p. 4-5)6. Entre as modificações do Código de 1917 que deveriam ser implantadas "[...] sem grandes despesas e com as devidas cautelas", estava "o programa especial para o grupo modelo" (SANTOS, 1917, p. 6).

O Programa do Grupo Escolar Modelo e Similares foi instituído pelo Decreto n. 420, de 19 de junho de 1917, depois da transformação do Grupo Escolar Xavier da Silva em Escola Modelo (PARANÁ, 1917a, art. 70, p. 30). A expectativa do Secretário dos Negócios do Interior, Justiça e Instrução Pública, Enéas Marques dos Santos, era que a Escola Modelo tornasse possível "começar a prática dos métodos escolares paulistas, sem perturbar a marcha do sistema de ensino em vigor" (PARANÁ, 1917b, p. 5-6). Entre as disciplinas do Programa, uma era a de Higiene?

Pré-requisito para uma vida sadia, para a boa constituição física do futuro cidadão, a atenção com a higiene estava presente no Código do Ensino de 1917 que, repetindo determinações editadas em 1915, estabelecia como obrigação do Conselho Superior do Ensino Primário "estudar e propor o que lhe parecer acertado em prol da higiene escolar". Os Delegados de Ensino, encarregados da "inspeção técnica das escolas primárias" e os Inspetores Escolares, que seriam médicos "sempre que for possível", deveriam observar com atenção a higiene dos estabelecimentos de ensino: prédio, mobiliário (como a carteira $\left.{ }^{8}\right)$, utensílios e outros materiais (PARANÁ, 1917a, art. 2 a 21, p. 10-18; art. 161, §único, p. 54). Mas era função do professor "zelar escrupulosamente pela conservação [da higiene em geral] mantendo em tudo o mais rigoroso asseio" (PARANÁ, 1917a, art.114, §VI, p. 41).

Essa ênfase na salubridade, ou seja, na higiene dos lugares e coisas, do Código do Ensino era explícita nas determinações detalhadas para os prédios

6 Desde o início do século XX professores, como Carolina Pinto Moreira em 1907, foram enviados pelo governo paranaense a São Paulo para estudar o modelo da escola graduada, uma prática que por vezes desagradou alguns educadores locais, provavelmente desejosos de firmar, em outros termos, a emancipação do estado do Paraná que até meados do século XIX foi comarca de São Paulo (Cf. ARAÚJO, 2013, p. 167-169).

7 Sobre disciplina, sinônimo de "matéria" e "disciplina escolar", confira Bittencourt (2003).

8 No Paraná, a carteira foi objeto da atenção destacada de educadores e de reivindicações de professores desde o início do século XX. Em seu relatório de 1916 o Secretário Enéas Marques dos Santos relatava: "Distribuí pelas escolas do Estado 1.170 carteiras, procurando, assim, melhorar as condições do mobiliário escolar, serviço esse que pretendo completar no ano próximo" (SANTOS, 1917, p. 4). A carteira foi tema de estudos médicos no Brasil (BERTUCCI, 2013, p. 229-231) e em outros países mereceu atenção especial também de arquitetos (BENCOSTTA, 2013). 
escolares. As prescrições, elaboradas com a perspectiva de construção de grupos escolares, afirmavam: a escola, com "todas as condições recomendadas pela pedagogia e pela higiene", deve ser construída em terreno amplo, com solo drenado que facilite o escoamento de água. $\mathrm{O}$ prédio no centro, rodeado por jardins, e com pátios de ginástica e recreio, além daquele para pias e latrinas estas últimas construídas de forma que "o máximo asseio fosse mantido" (com água e ventilação e segregadas das salas). As salas de aula de forma retangular, com amplas janelas de vidro (a superfície vítrea não inferior a um quarto da superfície da sala) e porão (nunca inferior a $1.50 \mathrm{~m}$ do chão ao assoalho), devem ser arejadas (o ar recebido diretamente do exterior) e ensolaradas (luz predominantemente do lado esquerdo do aluno), com espaço de $1.20 \mathrm{~m}$ por aluno (PARANÁ, 1917a, art. 157-164, p. 52-54).

Símbolo de um novo modelo escolar, os estabelecimentos de ensino construídos a partir desse ideal arquitetônico eram poucos no Paraná da segunda metade dos anos 1910 (BENCOSTTA, 2005) e, em 1916, meses antes da aprovação do novo Código do Ensino, o Secretário Enéas Marques dos Santos, em Relatório ao Presidente do Estado, tanto anunciava o funcionamento em dois turnos dos grupos escolares já existentes, para tentar acabar com as escolas isoladas próximas destes estabelecimentos de ensino; quanto afirmava a necessidade da "[...] construção de casas de escolas por modestas que sejam [até de madeira], nas colônias e nos pontos onde o recenseamento da população escolar já determinou serem indispensáveis as escolas", pois era preciso "[...] evitar o funcionamento de escolas em casebres que afugentam as próprias crianças" (SANTOS, 1917, p. 4) . $^{9}$ Tentativas díspares, mas complementares: os prédios dos grupos escolares e, enquanto fossem indispensáveis, as "casas de escolas" deveriam ser construções (limpas, arejadas e iluminadas) que atraíssem os alunos e conquistassem a aprovação de seus pais.

A salubridade, tema de considerações do Relatório do Secretário Enéas Marques dos Santos e de artigos do Código do Ensino, era parte do conteúdo da disciplina Higiene do Programa do Grupo Escolar Modelo e Similares. Nos tópicos Casas e Ruas, previstos para o $3^{\circ}$ ano da disciplina (o $4^{\circ}$ ano era para "ampliação" e revisão geral do conteúdo), o professor deveria ensinar a importância da construção das moradias em terrenos secos; "o valor" dos edifícios arejados, iluminados e sem umidade e a necessidade da limpeza das casas, com várias portas e janelas (estas imprescindíveis nos dormitórios). $\mathrm{O}$ abastecimento de água, a privada e o esgoto (ou uso de cal), fundamentais para

9 Em 1917, várias petições enviadas ao governo pelos professores de escolas isoladas solicitavam móveis e quadros-negros, além de instalações nos prédios de água corrente e privadas. (PETIÇÕES, 1917, n. 9, 21, 188, 260). 
uma vida sadia, também eram abordados no item Casas da disciplina Higiene, item que tinha como conclusão o tema "saúde dos moradores" explicitando a conjugação entre higiene pessoal e salubridade como meio para manutenção da saúde. Quanto ao tópico Ruas (e praças), que destacava a importância do alinhamento, largura e arborização das vias públicas, este item parecia auxiliar na educação dos alunos sobre salubridade e sua íntima relação com saúde das pessoas (PARANÁ, 1917b, p. 486).

É evidente a harmonia desses dois tópicos da disciplina Higiene, com determinações do Serviço Sanitário paranaense e ações da Profilaxia Rural do Paraná que, em consonância com diretrizes nacionais cada vez mais pautadas por demandas de sanitaristas (e em acordo com a Fundação Rockefeller), pretendiam sanear o Estado e sua população (HOCHMAN, 1998, p. 91-208; KUMMER, 2007, p. 32-54) ${ }^{10}$. Educar para a saúde era meta nacional e a partir desta perspectiva o desenvolvimento da disciplina Higiene do Programa do Grupo Escolar Modelo e Similares reiterava a instrução sobre temas que, paulatinamente, ganhavam complexidade nos anos escolares, procurando inculcar hábitos saudáveis nos alunos ${ }^{11}$.

Segundo este Programa, desde o $1^{\circ}$ ano as crianças deveriam ser ensinadas sobre os benefícios do banho e do asseio das roupas em geral; sobre a importância da limpeza das mãos, unhas e cabelos; dos olhos, orelhas, nariz (uso do lenço) e boca (escovar os dentes); sobre os resultados benéficos de deitar e levantar cedo (em dormitório ventilado) e da alimentação correta (qualidade, quantidade; o valor da mastigação) (PARANÁ, 1917b, p. 283-285). Casas e Ruas eram, portanto, tópicos que, no $3^{\circ}$ ano escolar, ampliavam essa formação para a saúde $^{12}$. Em 1922, o médico paulista Antonio de Almeida Junior, ao destacar o

10 Segundo o Decreto n.779, que organizou o Serviço de Profilaxia Rural paranaense em 1918, os professores primários deveriam ser "preparados em cursos especiais" para colaborar na empreitada educacional para a saúde (PARANÁ, 1918, p. 344). Sobre a atuação da Fundação Rockefeller no Brasil e em outros países latino-americanos, veja Cueto (1994) e Löwy (1999).

11 No capítulo Disposições Comuns às Escolas Maternais e aos Jardins da Infância do Código do Ensino de 1917, o artigo 35 determinava que o professor dirigisse "todos os exercícios e diversões" para que "as crianças adquiram hábitos de higiene", além de polidez, ordem e disciplina (PARANÁ, 1917a, art. 35, §IV, p. 20, grifo meu).

12 As mudanças curriculares sinalizadas pelo Programa do Grupo Escolar Modelo e Similares seriam graduais. Segundo o Código do Ensino de 1917, apenas na $4^{\text {a }}$ série do ensino primário os alunos deveriam aprender "noções fundamentais e práticas" de higiene, mas era dever dos alunos de todas as séries "cumprir os preceitos essenciais de higiene" e os professores, sempre que necessário, realizariam comentários e exercícios (cópia, ditado ou composição) sobre o tema (PARANÁ, 1917a, art. 55, §6, letra d, p. 26; art. 86, §VI; único, p. 32-33). Palavras estas que faziam eco com o Plano de Estudos da Escola Normal prescrito pelo Código, que estabelecia: os normalistas devem aprender noções de higiene "sucintas, limitadas, ao que [é] essencial na prática da vida” (PARANÁ, 1917a, art. 193, §11, p. 62). 
papel preponderante da escola primária para o saneamento da nação, escreveu que apenas a criança poderia ser efetivamente educada, pois somente ela seria suscetível a novos hábitos (BERTUCCI, 2013, p. 232). Poucos médicos e educadores desse período discordariam de Almeida Junior.

Assim, com o Programa do Grupo Escolar Modelo e Similares a escola primária como espaço privilegiado de educação para a saúde ganhou evidência no Paraná, entretanto, a forma como essa educação para a saúde deveria ser ministrada, do corpo (limpeza, alimentação, asseio do vestuário) até os espaços (da casa e da rua), ou seja, do individual para o geral, só poderia acontecer em prédios escolares que motivassem a higiene pessoal e a limpeza de lugares e coisas. Dos grupos escolares às "casas de escola", todas as construções nas quais funcionassem escolas primárias, "por modestos que sejam" - repetindo palavras do Secretário Enéas Marques dos Santos (SANTOS, 1917, p. 4) -, teriam que ser limpos e arejados, com água e banheiro.

\section{O costume}

Em meados de janeiro de 1917, menos de dez dias depois da aprovação do novo Código do Ensino e poucos meses antes da promulgação do Programa do Grupo Escolar Modelo e Similares, moradores do povoado da Graciosa de Baixo, situado à margem da estrada da Graciosa, ligação entre Curitiba e o litoral do Estado, enviaram petição ao Inspetor Escolar da região solicitando a reinstalação imediata da escola isolada do povoado que havia sido transferida para um novo prédio na cidade de Antonina. Justificavam: a escola prestava "bons proveitos" às crianças (60 meninos e meninas) da Graciosa de Baixo; a escola depois da transferência ficava distante cerca de 1 (um) quilômetro das casas de alguns alunos; a nova localização da escola trazia sérias dificuldades para a frequência de muitos "pequenos" e, por fim, que apenas com "muito sacrifício" poderiam as crianças frequentar uma escola da cidade (PROCESSO, 1917, p. 7).

Assinada por 44 pais de alunos, a argumentação foi classificada de "irrelevante" no relatório elaborado pelo Inspetor Escolar Antonio Gomes Junior, porque "nada alegam de ponderável, já para a instrução, já para a saúde da infância" (PROCESSO, 1917, p. 7). O Inspetor Escolar continuava suas considerações, que seriam enviadas junto com a petição ao Secretário Enéas Marques dos Santos, afirmando que a alegação sobre a distância da nova escola era inconsistente, considerando que a construção em Antonina ficava apenas a cerca de 400 metros da antiga escola do povoado - distância mais que aceitável, 
inclusive segundo as determinações do Código do Ensino recém-aprovado, que previa o máximo de 3 (três) quilômetros entre a casa do aluno e a escola para o comparecimento obrigatório às aulas (PROCESSO, 1917, p. 7. Cf.: PARANÁ, 1917 a, art. 42, §1, p. 21). As ponderações para a negativa ao pedido prosseguiram com o relato sobre a precariedade do antigo prédio da escola, edificado em local baixo, insalubre, de impaludismo endêmico, sem os "requisitos de capacidade e higiene exigidos pelo Código [de 1917]". Antonio Gomes Junior informava: há mais de três anos a construção de um novo local para que as aulas fossem ministradas, nas proximidades da própria escola, era prometida por particulares e pela municipalidade, mas nada de concreto aconteceu. Concluía esclarecendo que a transferência havia sido solicitada depois que a área em que estava a Escola da Graciosa de Baixo foi anexada ao perímetro urbano de Antonina, o que facilitou a mudança, pois a escola passara a fazer parte da cidade (PROCESSO, 1917, p. 11).

Todo esse caso havia começado em 14 de janeiro de 1917, quando a professora da Escola da Graciosa de Baixo, senhora Othilia Arantes Carneiro, encaminhou solicitação de transferência do estabelecimento de ensino ao Inspetor Escolar. Julgado pertinente por Antonio Gomes Júnior, o pedido foi remetido a Enéas Marques dos Santos, que aprovou a transferência em 19 de janeiro de 1917.

Mas o que pensavam os pais dos alunos que, poucos dias depois da assinatura da mudança da Escola da Graciosa de Baixo, solicitaram a volta da escola para o antigo prédio? Provavelmente tinham uma perspectiva diversa da questão. Os signatários da petição em nenhum momento mencionaram os problemas de salubridade, higiene e saúde que foram enfatizados pelo Inspetor Antonio Gomes Junior e acatados por Enéas Marques dos Santos. O texto da petição dos pais de alunos nos sugere que, mais que essas questões, o que importava era a facilidade e garantia de estudo de seus filhos. O total de 400 metros que separava a antiga da nova escola poderia ser um longo percurso na perspectiva paterna.

Frases do Inspetor Escolar escritas no Processo fornecem indícios sobre a percepção que Antonio Gomes Junior tinha do povoado da Graciosa de Baixo e de sua gente: "[...] no bairro todas as habitações são casebres"; "[...] a população ali composta de proletários, é muito atacada de moléstias epidêmicas" (PROCESSO, 1917, p. 7v. e 11). Considerando que pobreza e casas simples não são necessariamente causas de doenças, mesmo em região considerada insalubre; que as crianças não moravam (e não morariam) na escola, e que a diferença de 400 metros não as livraria, em princípio, do impaludismo (continuariam a circular pela área endêmica), é possível perguntar: teria sido a possibilidade de educação sanitária (inclusive dos pais), materializada no novo prédio escolar, um poderoso, mas não explicitado, argumento para a transferência? 
Declarando querer bem desempenhar a "alta missão" que havia lhe confiado o governo estadual, o Inspetor Escolar informava ao Secretário Enéas Marques dos Santos que "os reclamantes, pessoas rústicas, não alcançaram a enorme conveniência desta mudança para a infância escolar [...]" (PROCESSO, 1917, p. 7). Para Antonio Gomes Júnior as "pessoas rústicas"13 da Graciosa de Baixo precisavam de educação, considerando os argumentos usados para defender a transferência escolar durante o processo de mudanças, inclusive de educação para a manutenção da saúde. Entretanto, o que ficava evidente é que não bastava, como aparentemente supunha o Secretário do Interior, "evitar o funcionamento de escolas em casebres" para manter crianças na sala de aula (SANTOS, 1917, p. 4).

Elaborada pelo Inspetor Escolar logo depois de receber a petição dos moradores, a defesa da transferência, que resultou na permanência da escola no novo local, foi escrita a partir de uma confirmação ${ }^{14}$. Em 24 de janeiro, Antonio Gomes Júnior solicitou a Othilia Arantes Carneiro nova e brevíssima confirmação dos motivos que concorreram para o pedido de mudança de prédio escolar. A professora respondeu dois dias depois, de próprio punho:

tenho a $\mathrm{V}^{\mathrm{a}} \mathrm{S}$ informar que solicitei a transferência não só porque o local é insalubre, como porque as casas ali são pequenas e sem privadas e também porque o proprietário tinha um porquinho que andava sempre na sala de aula prejudicando a marcha dos trabalhos escolares (PROCESSO, 1917, p. 6-6v.).

Os moradores da Graciosa de Baixo eram caboclos paranaenses - como, indistintamente, foram denominados os habitantes do meio rural do Estado por médicos-sanitaristas (KUMMER, 2007, p. 56) -, com seu modo de vida "rústico", pessoas em geral analfabetas, vivendo da exploração da terra e, muitas vezes, da pesca (KUMMER, 2007, p.57-69), os quais habitavam a região de

13 Em estudos sociológicos sobre o início do século XX, rústico, sertanejo, caboclo e caipira são termos que sinalizam "contato interétnico [e cultural] do branco português com o indígena brasileiro" (KUMMER, 2007, p. 59).

14 O Inspetor Escolar também anunciou no final de suas considerações ao Secretário Enéas Marques dos Santos: "não foram só as supra, as altas razões de higiene e de governo que aconselharam a transferência em questão, e sim outra também de excepcional importância que levo ao conhecimento de V. Exa em comunicado confidencial." A razão confidencial foi transmitida a Antonio Gomes Júnior pela professora Othilia Arantes Carneiro. O sigilo foi mantido (PROCESSO, 1917, p. 6v. e 8). 
Antonina, que desde o final do século XIX recebeu imigrantes estrangeiros, a maioria italianos, que traziam novos costumes para o local (MARTINS, 1941, p. 150-152, 160-161). Pessoas que, em tempos de transformações permeadas pela paulatina ocupação e reordenação da área que habitavam (inclusive com a incorporação da área à cidade de Antonina), valorizavam a educação dos filhos o suficiente para se mobilizarem contra a determinação oficial que transferia a Escola da Graciosa de Baixo para Antonina.

Como entender esse grupo de indivíduos capaz de se organizar e fazer um abaixo-assinado (quantos assinaram de próprio punho não sabemos), mas que preferia que seus filhos estudassem em local considerado insalubre e que "sempre", segundo a professora, era invadido por um porquinho? Na petição, os pais dos alunos da Escola da Graciosa de Baixo afirmavam que seria com "muito sacrifício" que seus filhos se apresentariam em uma escola de Antonina. Aparentemente sentiam que a apenas 400 metros do antigo local de ensino seus filhos sofreriam. Mas o quê? O Inspetor Escolar pode nos ajudar a elucidar a questão: ele, prudentemente, reiterou para a professora Othilia Arantes Carneiro a determinação do Código do Ensino que prescrevia a proteção de crianças pobres e de trajes humildes de toda a discriminação, e mais, Antonio Gomes Júnior determinou que apenas crianças da antiga Escola da Graciosa de Baixo fossem matriculadas na nova escola, garantindo não apenas a matrícula dessas crianças, mas tranquilizando os pais que deixassem seus filhos estudar em Antonina (PROCESSO, 1917, p. 7v. Cf.: PARANÁ, 1917a, art. 81, p. 32).

Dessa forma, a reação de um grupo de pessoas às mudanças aparentemente benéficas para seus filhos ganha nova dimensão, quando percebida como resultado de um processo que combinava a importância que os pais dos alunos da Escola da Graciosa de Baixo atribuíam à educação (algo certamente aplaudido pelo governo) com peculiaridades de um modo de vida "rústico" que poderia gerar desconforto nos seus filhos caso fossem estudar em Antonina. Para os pais desses alunos um local de ensino que garantisse o respeito por seus costumes era mais importante do que um prédio escolar considerado adequado pelos padrões higiênicos de médicos, educadores e autoridades governamentais.

A escola mudou para o prédio de Antonina, mas com expressa declaração para que fosse observado o artigo do Código do Ensino que garantia a proteção aos alunos "pobres" e com a garantia de exclusividade de matrícula para os filhos dos moradores da Graciosa de Baixo. Como escreveu Edward P. Thompson, as forças e a retórica da lei, "às vezes, inibem o poder e oferecem alguma proteção aos destituídos de poder [...]; a lei não foi apenas imposta de cima sobre os homens: tem sido um meio onde outros conflitos sociais têm se travado" (THOMPSON, 1987, p. 358). 


\section{A lei e o costume. Considerações finais}

Escola transferida, processo encerrado. Mas as palavras da professora Othilia Arantes Carneiro, escritas para justificar a mudança da Escola da Graciosa de Baixo para o prédio de Antonina, ainda motivam um questionamento: como entender que a professora tenha escrito de próprio punho que "[...] um porquinho andava sempre na sala de aula prejudicando a marcha dos trabalhos escolares"? (PROCESSO, 1917, p. 6). Nenhuma palavra sobre o prejuízo que tal ocorrência poderia trazer para a higiene do local e para a saúde dos alunos e dela própria, apenas a lembrança da confusão que o acontecimento trazia para as atividades de ensino. O Inspetor Escolar não comentou o caso.

É preciso considerar que nos primeiros anos do século $\mathrm{XX}$, em terras paranaenses e outras partes do território nacional, poucas eram as pessoas, ricas ou pobres, instruídas (como a professora) ou analfabetas que não conheciam criadores de porcos, muitas vezes instalados bem próximos das moradias. Indício desse costume está nas Posturas Municipais de Curitiba de 1895, que tentavam coibir tal prática no seu Título "Da higiene e salubridade pública" que proibia "criar, ter ou conservar" porcos nos quintais das casas do "quadrado urbano" da capital (POSTURA, 1895, p. 110). Em 1918, cerca de um ano e meio depois do caso da transferência da Escola para Antonina, o Serviço de Profilaxia Rural do Paraná determinava: "No perímetro urbano das cidades e vilas serão proibidos os chiqueiros, permitidos entretanto nos arrabaldes, nos povoados e colônias rurais [...]". Exigências de piso impermeabilizado e água corrente ou da distância mínima de 100 metros das habitações tentavam garantir boas condições sanitárias (PARANÁ, 1918, art. 20, p. 347-348).

Assim, o caso do porquinho que circulava pela Escola da Graciosa de Baixo não invalida as intenções de Othilia Arantes Carneiro que, em consonância com as teses médico-educacionais do período, expressou repetidamente (até na primeira frase do parágrafo manuscrito do Processo) convicção nos benefícios da salubridade e higiene para a manutenção da saúde. Mas este caso evidencia como práticas cotidianas, amplamente difundidas, balizavam a incorporação (e efetivação) de ações diárias relativas à saúde. Palavras escritas rapidamente para responder ao Inspetor Escolar podem revelar mais que longas e elaboradas declarações; podem mostrar como mudar era muito mais complexo do que poderiam supor alguns médicos, educadores e governantes.

Desde o final do século XIX a divulgação cada vez mais intensa (pelos jornais, dicionários de medicina popular, etc.) da conjugação limpeza e saúde e da identificação da sujeira como fator que concorreria para o alastramento 
de doenças colaborou para que novos padrões de higiene e salubridade fossem paulatinamente incorporados pela população no Paraná (BERTUCCI, 2011). Em 1902, por exemplo, o jornal de Curitiba A República afirmava, ao noticiar a peste bubônica no porto de Paranaguá: "a população curitibana deve lembrar-se agora de que a boa higiene é o principal preservativo contra a peste [...]" ( $A$ República, 27 fev. 1902, p. 2, apud BERTUCCI, 2011, p. 6). Mas esse processo formador para a saúde, que teve na escola primária importante meio de efetivação, também foi combinado ou balizado de maneira difusa e permanente por costumes partilhados por pessoas de diferentes grupos sociais; por uma ambiência (THOMPSON, 1998, p. 14) plena de tradições vividas cotidianamente, que em mais de um aspecto os saberes médico-sanitários condenavam ${ }^{15}$.

O Código do Ensino e o Programa do Grupo Escolar Modelo e Similares, ambos de 1917, e as múltiplas facetas do caso da transferência da Escola da Graciosa de Baixo exemplificam o sinuoso percurso dos que pleiteavam a formação do homem nacional saudável. No Paraná, a atitude de "pessoas rústicas", que alardeavam a importância da educação de seus filhos, motivou esclarecimento governamental e resultou em vagas escolares exclusivas para estudantes oriundos de um povoado. Paralelamente, a professora que, baseada em argumentos médico-sanitários, solicitou a transferência da Escola da Graciosa de Baixo para um prédio salubre não fez comentário sobre as possíveis repercussões desastrosas para a saúde que poderiam ser causadas pela circulação de um porquinho em uma sala de aula. Caso significativo para percebermos como tanto as determinações legais como sua efetivação resultam de um processo social, marcado por aceitações, reivindicações e contestações de indivíduos que, com sua prática diária, motivam a elaboração legislativa e, também, delimitam sua efetivação.

\section{REFERÊNCIAS}

ALBUQUERQUE, C. C. de. Mensagem - Presidente do Estado do Paraná. $1^{\circ}$ de fevereiro de 1916. Curytiba: Typ. Diario Official, 1916. (Arquivo Público do Estado - Curitiba, PR).

ARAUJO, S. A. C. de. Professora Julia Wanderley: uma mulher-mito (1874-1918). Curitiba: Ed. UFPR, 2013.

15 Valores e crenças, de ricos e pobres, sobre cuidados com a saúde e para combater as doenças (em geral misturando rezas, chás e ervas), eram repetidamente condenados pelos médicos de diferentes partes do Brasil e causavam estranhamento em doutores e leigos que acreditavam em um poder absoluto da ciência médica e da educação para a saúde realizada, cotidianamente, pela escola e outros meios (Cf. BERTUCCI, 2003). 
BENCOSTTA, M. L. A. Arquitetura e espaço escolar: o exemplo dos primeiros grupos escolares de Curitiba (1903-1928). In: BENCOSTTA, M. L. A. (Org.). História da educação, arquitetura e espaço escolar. São Paulo: Cortez, 2005, p. 95-140.

BENCOSTTA, M. L. A. Mobiliário escolar francês e os projetos vanguardistas de Jean Prouvé e André Luçat na primeira metade do século XX. Educar em Revista, Curitiba, n. 49, p. 19-38, 2013.

BERTUCCI, L. M. Forjar o povo, construir a nação: ciência médica e saúde pública no Brasil. In: RIBEIRA CARDÓ, E. et al. (Coord.). La integración del territorio en una idea de Estado, México y Brasil, 1821-1946. Ciudad de México: IG/UNAM; Instituto Mora, 2007, p.141-161.

BERTUCCI, L. M. Remédios, charlatanices... e curandeirices. In: CHALHOUB, S. et al. (Org.). Artes e oficios de curar no Brasil. Campinas: Ed.Unicamp, 2003, p.197-227.

BERTUCCI, L. M. Sanear a raça pela educação. Teses da Faculdade de Medicina e Cirurgia de São Paulo, início dos anos 1920. In: MOTA, A.; MARINHO, M. G. S. M.C. (Org.). Eugenia e história. São Paulo: FFMUSP; UFABC; Casa de Soluções e Editora, 2013, p. 219-238.

BERTUCCI, L. M. Saúde pública na Capital paranaense: Considerações sobre as primeiras décadas do período republicano. Texto inédito, ago. 2011.

BITTENCOURT, C. M. F. Disciplinas escolares: história e pesquisa. In: OLIVEIRA, M. A. T.; RANZI, S. (Org.). História das disciplinas escolares no Brasil. Bragança Paulista: Edusf, 2003, p. 9-38.

BONI, M. I. M. de. O espetáculo visto do alto. Vigilância e punição em Curitiba, 18901920. Curitiba: Aos Quatro Ventos, 1998.

BUENO, W. de L. Uma cidade bem amanhecida. Vivência e trabalho das mulheres polonesas em Curitiba. 2. ed. Curitiba: Aos Quatro Ventos, 2004.

CASTRO, E. A. de. Grupos escolares de Curitiba na primeira metade do século XX. Curitiba: Edição do autor, 2008.

CERTEAU, M. de. A invenção do cotidiano. As artes do fazer. 17. ed. Petrópolis: Vozes, 2011.

CORBIN, A. Saberes e odores. São Paulo: Companhia das Letras, 1987.

CUETO, M. (Ed.). Missionaries of science. Indianápolis: Indiana University Press, 1994.

CZERESNIA, D. Do Contágio à transmissão. Rio de Janeiro: Editora Fiocruz, 1997.

DOMINGUES, H. M. B.; SÁ, M. R.; GLICK, T. (Org.). A recepção do darwinismo no Brasil. Rio de Janeiro: Ed. Fiocruz, 2003.

FERREIRA, L. O. Uma interpretação higienista do Brasil imperial. In: HEIZER, A.; VIDEIRA, A. A. P. (Org.). Ciência, civilização e império nos trópicos. Rio de Janeiro: Access, 2001. p. 207-223. 
GONDRA, J. G. Medicina, higiene e educação escolar. In: LOPES, E. M. T.; FARIA FILHO, L. M. de; VEIGA, C. G. (Org.). 500 anos de educação no Brasil. 2. ed. Belo Horizonte: Autêntica, 2000. p. 519-550.

HOCHMAN, G. A era do saneamento. São Paulo: Hucitec,1998.

JANZ JUNIOR, D. C. Eugenia em terras paranaenses: o médico Milton de Macedo Munhoz (1920-1940). In: MOTA, A.; MARINHO, M. G. S. M. C. (Org.). Eugenia e história: ciência, educação e regionalidades. São Paulo: FFMUSP; UFABC; Casa de Soluções e Editora, 2013, p. 287-306.

KUMMER, C. S. da F. Não esmorecer para não desmerecer. Mestrado (Dissertação em História) - Departamento de História, Universidade Federal do Paraná. Curitiba, 2007.

LAMB, R. D. Uma jornada civilizadora. 2. ed. Curitiba: Aos Quatro Ventos, 1999.

LATOUR, B. Pasteur. Paris: Perrin, 1994.

LAVALlE, A. M. A madeira na economia paranaense. Curitiba: Grafipar, 1981.

LIMA, N. T. de; HOCHMAN, G. Condenado pela raça, absolvido pela medicina. In: MAIO, M. C.; SANTOS, R. (Org.). Raça, ciência e sociedade. Rio de Janeiro: Ed. Fiocruz, 1996. p. 23-40.

LOPES, A. de P. C. Das escolas reunidas ao grupo escolar. In: VIDAL, D. G. (Org.). Grupos escolares. Campinas: Mercado das Letras, 2006. p. 81-107.

LÖWY, I. Representação e interpretação em saúde pública: virus, mosquito e especialistas da Fundação Rockefeller no Brasil. História, Ciências, Saúde - Manguinhos. Rio de Janeiro, v. 5, n. 3, p. 647-677, nov. 1998; fev. 1999.

LUZ, R. M. A modernização da sociedade no discurso do empresariado paranaense. Curitiba, 1890-1920. Dissertação (Mestrado em História) - Departamento de História, Universidade Federal do Paraná. Curitiba, 1992.

MAIO, M. C.; SANTOS, R. V. (Org.). Raça, ciência e sociedade. Rio de Janeiro: Ed. Fiocruz, 1996.

MARQUES, V. R. B. A inspeção médico-escolar no Paraná dos anos 1920: o apostolado de médicos e professores. In: DINIS, N. F.; BERTUCCI, L. M. (Org.). Múltiplas faces do educar. Curitiba, Ed. UFPR, 2007. p. 125-136.

MARQUES, V. R. B. A medicalização da raça. Campinas: Ed. Unicamp, 1994.

MARTINS, R. Quantos somos e quem somos. Curitiba: Emp. Gráfica Paranaense, 1941.

MONARCHA, C. Escola Normal da Praça. Campinas: Ed. Unicamp, 1999.

MOREIRA, C. P. Relatório apresentado ao Presidente do Estado do Paraná João Candido Ferreira, em 1907. (Arquivo Público do Estado - Curitiba, PR).

MOTA, A. Quem é bom já nasce feito. Rio de Janeiro: DP\&A, 2003. 
NAXARA, M. R. C. Estrangeiro em sua própria terra. Representações do brasileiro 1870/1920. São Paulo: Annablume, 1998.

OLIVEIRA, M. A. T. de; MEURER, S. dos S. Tensões entre o prescrito e o realizado na escolarização paranaense na década inicial do século XX. In: OLIVEIRA, M. A. T. de (Org.). Cinco estudos em história e historiografia da educação. Belo Horizonte: Autêntica, 2007. p. 69-88.

PARANÁ. Decreto n. 17, Código do Ensino, em 9 de janeiro de 1917. Leis, decretos e regulamentos. Curytiba: [s.n.], p. 9-91a.

PARANÁ. Decreto n. 420, Programa do Grupo Escolar Modelo e Similares, em 19 de junho de 1917. Leis, decretos e regulamentos. Curytiba, [s. n.], p. 222-285b.

PARANÁ. Decreto n. 710, Código do Ensino, 18 de outubro de 1915. Leis, decretos e regulamentos. Curytiba: [s.n.], p. 335-395.

PARANÁ. Decreto n. 779, Cria no Paraná o Serviço de Profilaxia Rural, em 8 de outubro de 1918. Leis, decretos e regulamentos. Curytiba, [s. n.], p. 343-371.

PEREIRA, M. R. de M. Semeando iras rumo ao progresso. Curitiba: Ed. UFPR, 1996. PETIÇÕES. Secretário dos Negócios do Interior, Justiça e Instrução Pública, Paraná. Inspetores de Ensino, AP 1645, n. 21, 188 e 260. AP 1647, n. 9. (Arquivo Público do Estado - Curitiba, PR).

POSTURA. Câmara Municipal de Curitiba - 1895. In: PEREIRA, M. R. de M. (Org.). Posturas municipais - Paraná, 1829 a 1895. Curitiba: Aos Quatro Ventos, 2003. p. 103-143.

PROCESSO. Transferência da Escola da Graciosa de Baixo, 1917. AP 1645. (Arquivo Público do Estado - Curitiba, PR).

PYKOSZ, L. C.; OLIVEIRA, M. A. T. de. A higiene como tempo e lugar da educação do corpo: preceitos higiênicos no currículo dos grupos escolares do estado do Paraná. Currículo sem Fronteiras, online, v. 9, n. 1, p. 135-158, jan./jun. 2009.

ROCHA, H. H. P. A higienização dos costumes. Campinas: Mercado das Letras, 2003.

ROSEN, G. Uma história da saúde pública. São Paulo: Ed. Unesp, 1994.

ROSS, S. de. Paraná-Médico (1916-1930): intelectuais em defesa da ciência médica e da educação dos habitantes do meio rural. Dissertação (Mestrado em Educação) - Setor de Educação, Universidade Federal do Paraná. Curitiba, 2012.

SÁ, D. M. de. Uma interpretação do Brasil como doença e rotina: a repercussão do relatório médico de Arthur Neiva e Belisário Penna (1917-1935). História, Ciências, Saúde-Manguinhos. Rio de Janeiro, v. 16, Suplemento 1, p. 183-203, jul. 2009.

SANTOS, E. M. dos. Relatório apresentado ao Exmo. Snr. Dr. Affonso Alves de Camargo, Presidente do Estado. 1916. Coritiba: Typ. d' "A República", 1917. (Arquivo Público do Estado - Curitiba, PR). 
SCHWARCZ, L. M. O espetáculo das raças. São Paulo: Companhia das Letras, 1993.

SOLOMON-BAYET, C. S. (Org.). Pasteur et la revolution pasteurianner. Paris: Payot, 1986.

SOUZA, R. F. de. História da organização do trabalho escolar e do currículo no século XX. São Paulo: Cortez, 2008.

SOUZA, R. F. de. Templos de civilização. São Paulo: Ed. Unesp, 1998.

STEPAN, N. L. Eugenia no Brasil, 1917-1940. In: HOCHMAN, G.; ARMUS, D. (Org.). Cuidar, controlar, curar. Rio de Janeiro: Ed. Fiocruz, 2004. p. 331-391.

STERN, I. As campanhas de prevenção às doenças e sua ação educativa. Dissertação (Mestrado em Educação) - Setor de Educação, Universidade Federal do Paraná. Curitiba, 2003.

THOMPSON, E. P. Costumes em comum. São Paulo: Companhia das Letras, 1998.

THOMPSON, E. P. Senhores e caçadores. São Paulo: Paz e Terra, 1987.

VIDAL, D. G. (Org.). Grupos escolares. Campinas: Mercado de Letras, 2006.

WEGNER, R.; SOUZA, V. S. de. Eugenia "negativa", psiquiatria e catolicismo: embates em torno da esterilização eugênica no Brasil. História, Ciências, Saúde - Manguinhos. Rio de Janeiro, v. 20, n. 1, p. 263-288, jan./mar. 2013.

Texto recebido em 15 de outubro de 2014. Texto aprovado em 21 de outubro de 2014. 